\title{
Postoperative Therapy for Metacarpophalangeal Arthroplasty
}

\author{
Nicola Massy-Westropp \\ School of Health Sciences, University of South Australia \\ Australia
}

\section{Introduction}

Since the earliest metacarpophalangeal (MCP) arthroplasties in the 1950s, numerous resurfacing and excisional arthroplasties, and a greater choice of surgical tools and techniques to implant the prostheses have become available. Of the excisional arthroplasties, one-piece and two-piece hinge designs, constrained by screws or unconstrained, cemented and non-cemented, have been designed (1) Surgeons now perform these procedures as day surgery, and leave as much original bone as possible in the likelihood of replacing the prosthesis as the patient ages.

At the time of surgery, synovectomy and soft-tissue balancing procedures are often performed to increase lateral joint stability or enhance the biomechanical advantage of the tendons around the operated joint. These procedures may necessitate post-operative immobilisation, specific joint positioning and strict motion protocols to achieve the best soft tissue range of motion and stability around the prosthesis (2-6).

The efficacy of postoperative therapy regimens also requires research, as they affect patient outcome, and are time-consuming and expensive. The aim of this review is to determine which postoperative regimen are most effective in achieving freedom from pain and function, and if any particular regimen is best suited to a specific prosthesis or soft-tissue balancing procedure at the time of surgery.

\section{Method}

For inclusion in this review, studies had to evaluate the efficacy of a post-arthroplasty regimen for patients who had metacarpophalangeal or joint arthroplasty. Preferred study designs were metanalyses, systematic reviews, and randomised controlled trials, but all published literature except expert opinion was accepted. Patients may have received any type of implant and soft-tissue procedure, due to rheumatoid arthritis, osteoarthritis or trauma.

Electronic databases searched were the Cochrane Musculoskeletal Disease Group Register, The Cochrane Library of Systematic review, Google Scholar, and Scopus. Manual searches included of the Journal of Hand Therapy, Hand Therapy and the Journal of Arthroplasty. Search terms in all combinations included 'joint replacement, hand, wrist metacarpophalangeal, arthroplasty, rehabilitation, post-operative, occupational therapy, physical therapy'. The search included papers from 1990 onward, aiming to find research about currently used prostheses and not prostheses of older designs and materials. 
Studies were appraised as described by the Cochrane Collaboration (7) for sources of methodological bias that could decrease the internal validity of a study. The types of methodological bias were in patient selection, equality of treatment, attrition of patients, and detection of all relevant outcomes. If the study could not be fully appraised from the publication, information was sought by writing to the authors.

\section{Results}

Sixteen studies described post-operative therapy for MCP joint replacement in enough detail to understand the treatment schedule. Four hundred and twenty-seven patients in these studies had rheumatoid arthritis, 19 had osteoarthritis and one had psoriatic arthritis. There were four randomised trials (one about post-operative therapy), three prospective cohort studies, three prospective case series (two about post-operative therapy), one case study about post-operative therapy, and the remaining were retrospective case series. Missing data was obtained from two authors, to assist in reviewing the rigour of the studies, but many authors could not be contacted.

The randomised controlled trial study found to specifically compare post-operative regimes for metacarpophalangeal arthroplasty (8) randomised patients into postoperative therapy groups that both included dynamic splinting, but the treatment group also included continuous passive motion. These researchers found no difference between treatment groups. Thomsen, Boeckstyns and Leth-Espensen(2003) (9) and retrospectively reviewed consectutive patients who had either dynamic MCP extension splinting, or had static splinting that was removed for exercises post-operatively. They found that residual extension lag was significantly less $(p=0.002)$ in the dynamicallysplinted group, concluding that postoperative dynamic splinting was useful. Groth, Watkins and Paynter, (1996)(10) retrospectively compared patients who had dynamic flexion with those who had dynamic extension splinting, and found that those who had post-operative dynamic flexion splinting had greater post-operative MCP flexion. Burr, Pratt and Smith (2002)(11), Burr and Pratt (1999)(12) focussed their research on postoperative therapy, but neither study had a comparison treatment group. No further studies compared post-operative treatment regimes, therefore the results of the remaining studies can only be appreciated as a combination of surgery, implant and post-operative therapy.

One outcome common to nearly all postoperative patients in every study was the relief of pain once the diseased joint had been removed by surgery. Negative outcomes such as wound infection, implant loosening and migration were reported, in small proportions. Compliance with splinting and therapy was not discussed. Sixteen studies described the outcome of different implants and postoperative therapy regimes for MCP arthroplasty.

Features common to many regimens (Table 1) were postoperative avoidance of any hand activity for the first three to six weeks and long-term avoidance of ulnar forces on the fingers. Nearly all regimens began between the second and seventh postoperative day.

Regimens could be divided into two main categories with regard to splinting and exercise. Static splint regimens involved removal of the splint for active MCP range of motion exercises, and dynamic splint regimens involved active-assisted MCP extension and active MCP flexion exercises within the splint. 


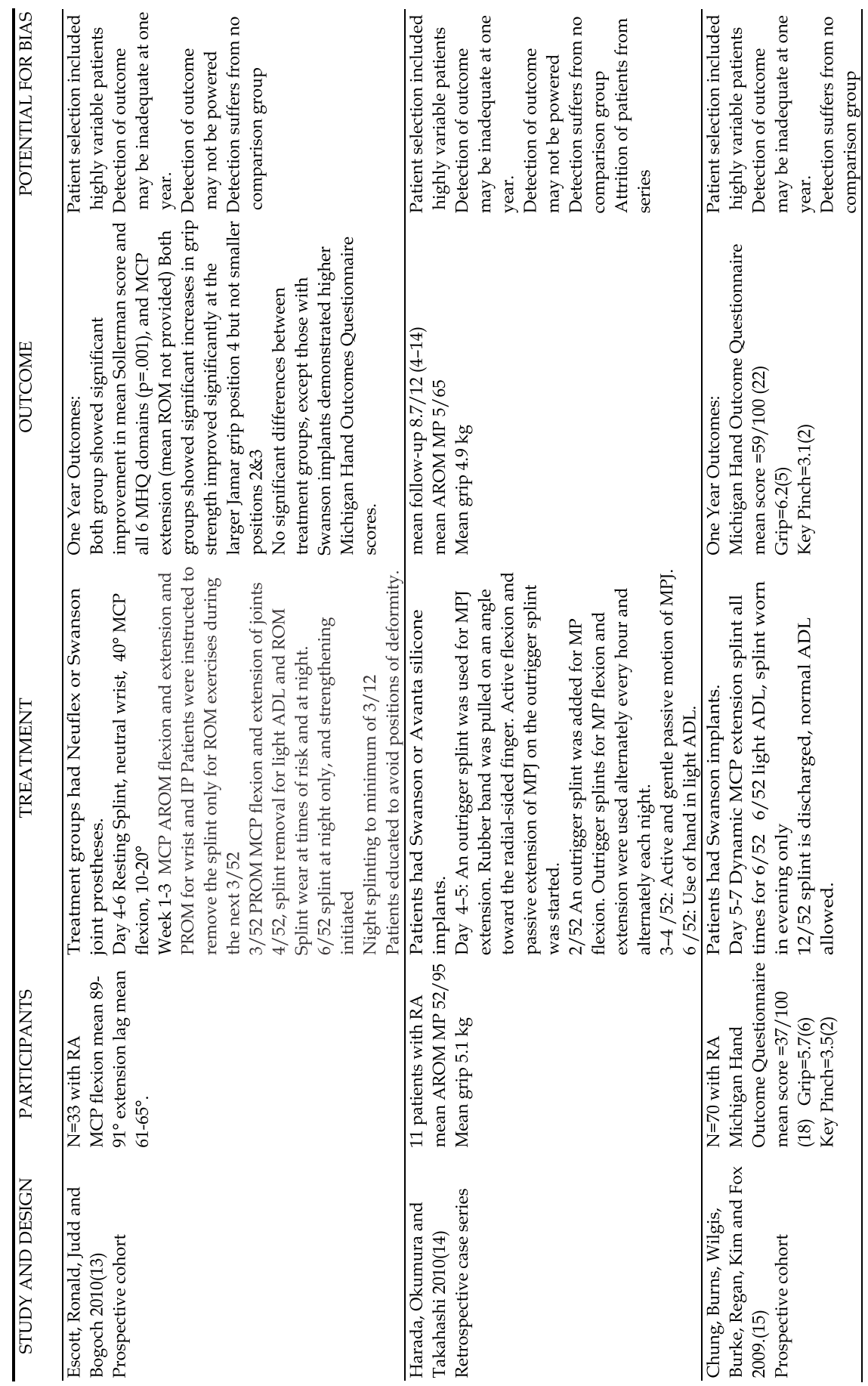




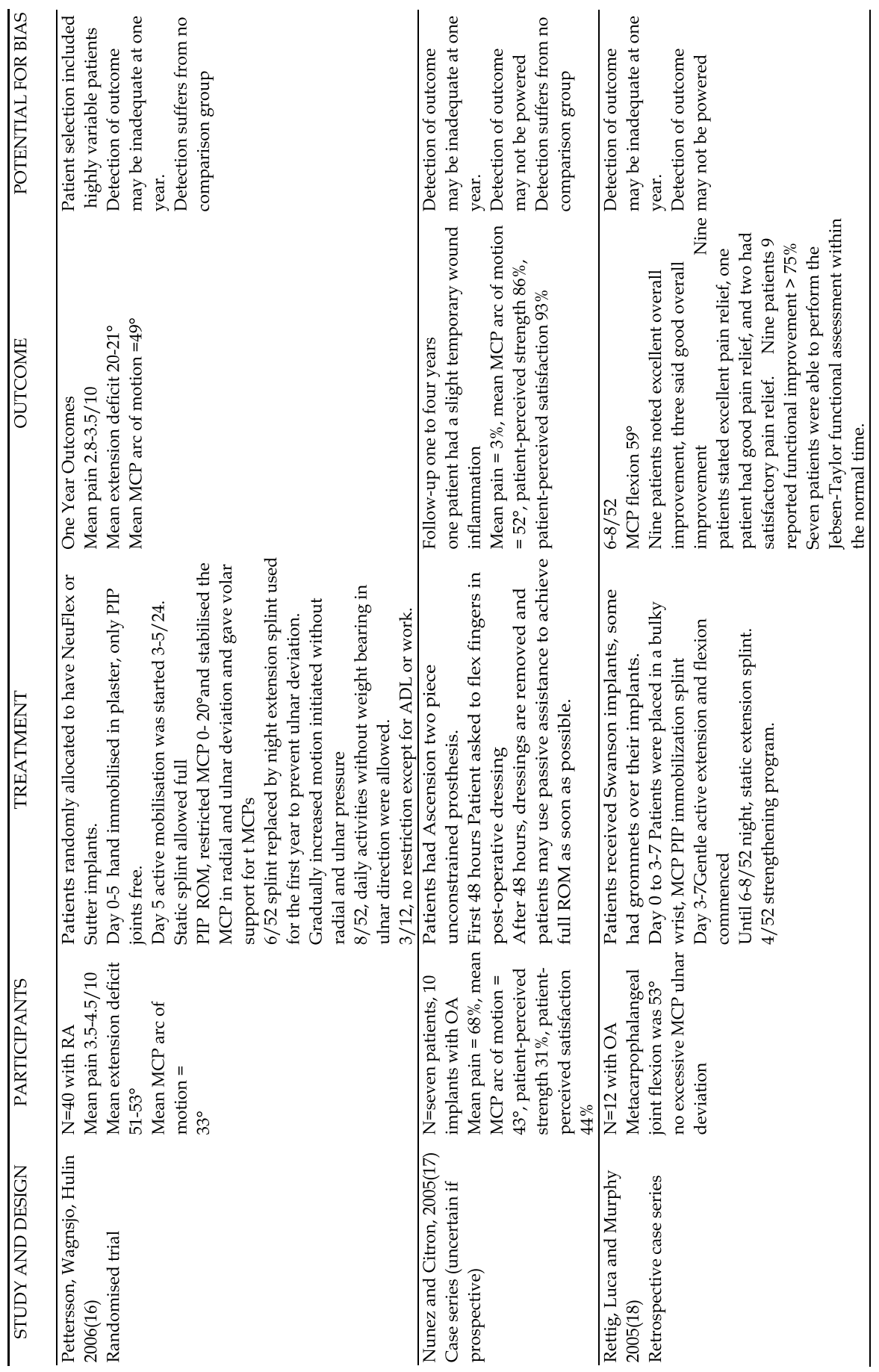




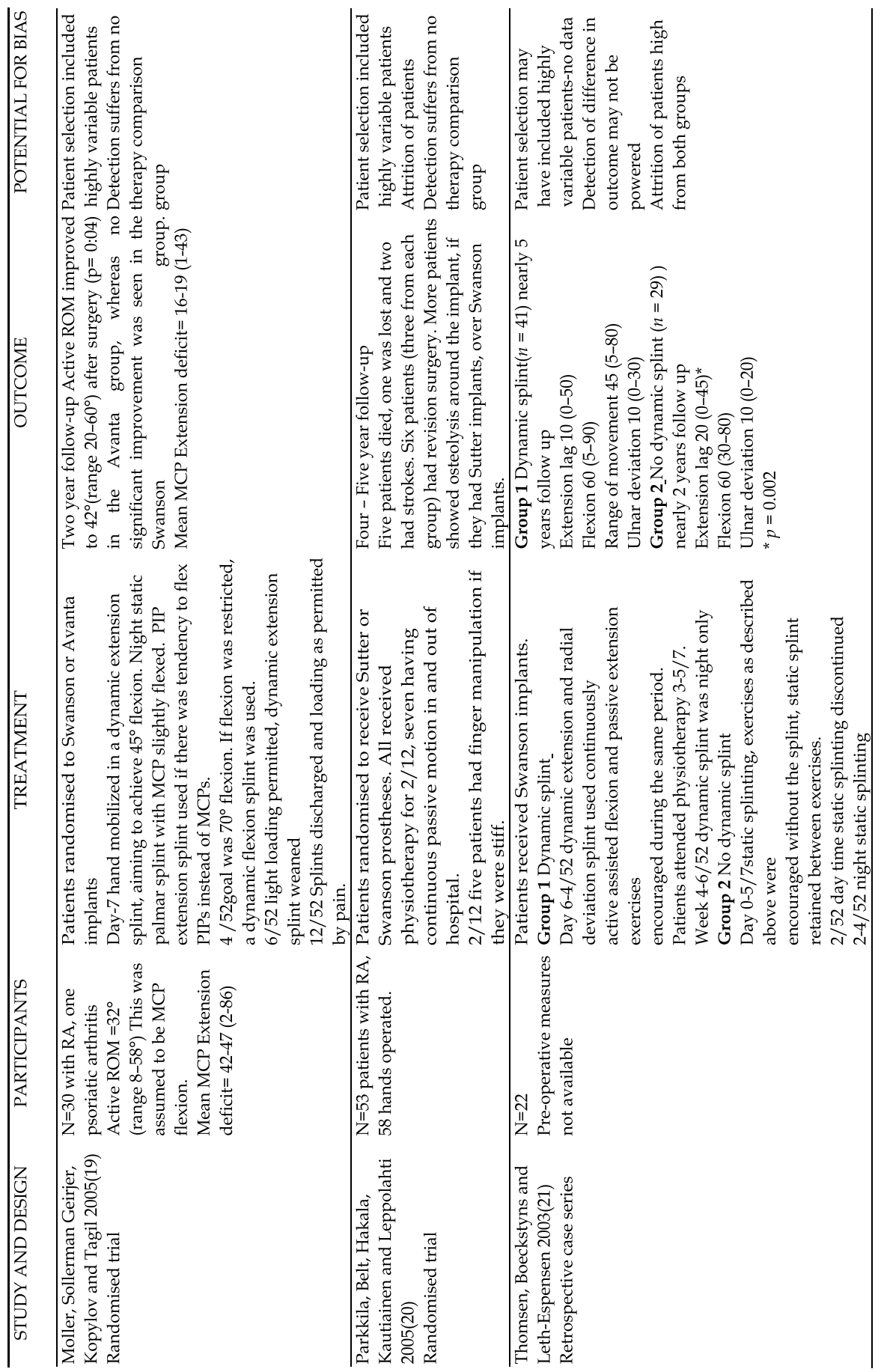




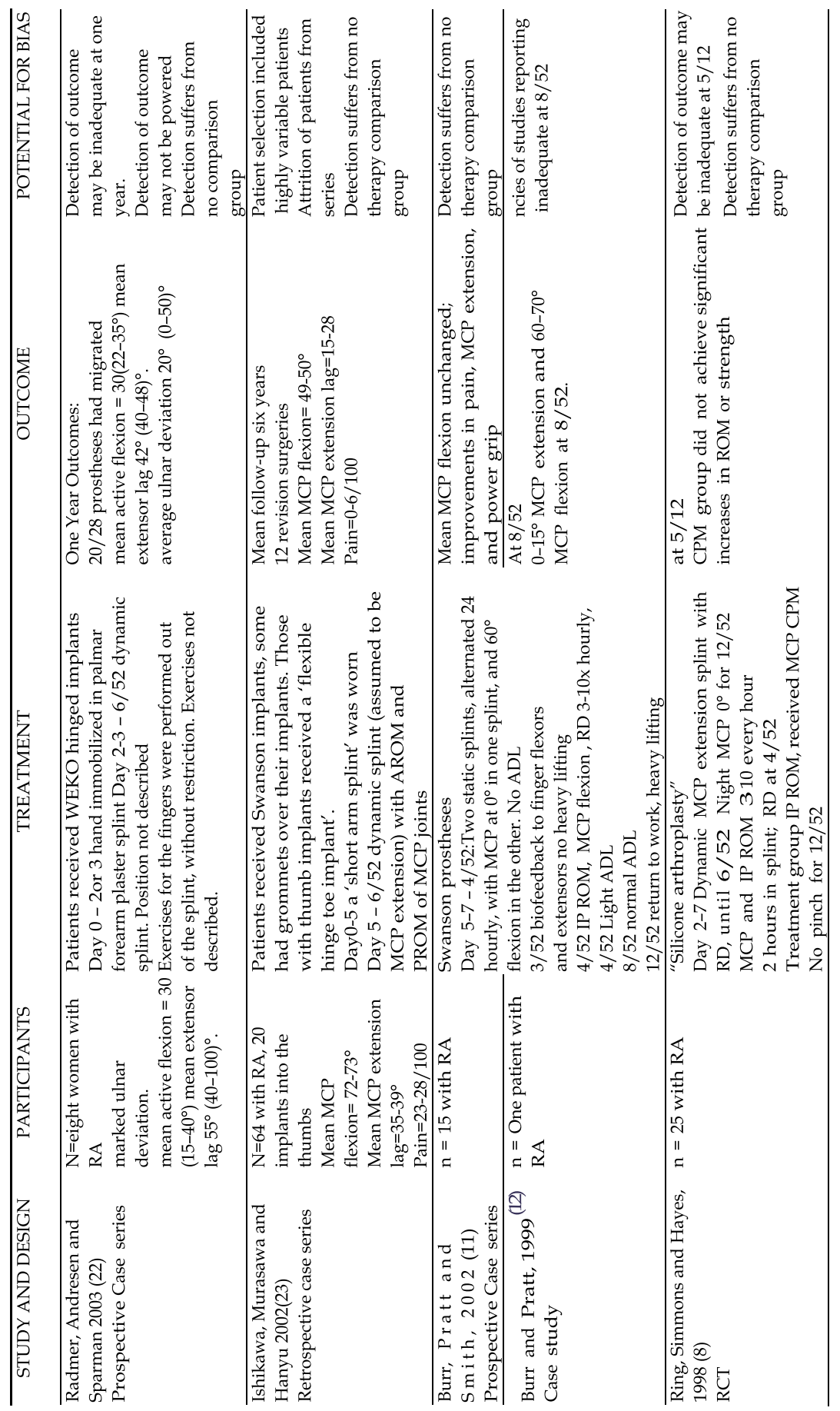




\begin{tabular}{|c|c|c|c|}
\hline STUDY AND DESIGN & PARTICIPANTS & TREATMENT & OUTCOME \\
\hline $\begin{array}{l}\text { Groth, Watkins and Paynter, } \\
1996 \text { (10) Retrospective } \\
\text { case series }\end{array}$ & $\begin{array}{l}\mathrm{n}=34 \text { patients, } 46 \\
\text { hands with } \mathrm{RA}\end{array}$ & $\begin{array}{l}\text { Timing not recorded } \\
\text { Treatment group } \\
\text { Dynamic MCP flexion splint } \\
\text { Night static splint, MCP } 20-30^{\circ} \text { flexion }\end{array}$ & $\begin{array}{l}\text { Uncertain of follow-up durati } \\
\text { Treatment group had sigr } \\
\text { MCP flexion than cohort, } \\
\text { MCP extension }\end{array}$ \\
\hline
\end{tabular}

Stothard, Thompson and Sherris 1991

(Prospective cohort
$\mathrm{N}=25$ patients with RA Thirteen patients had Swanson MCP implants and crossed Mean ulnar deviation preoperatively $34^{\circ}$ intrinsic transfer, 12 patients had MCP implant only. Day 3 static resting hand splint with high ulnar borders for all patients, removed four times daily for active radial deviation, flexion and extension. Day 8-10 PROM; no further details

$3 / 52$ splint worn at night only, light ADL

4/52 commenced occupational therapy, no further details

\section{Follow-up 6-33/12}

Five patients lost to follow-up

Mean ulnar deviation $8^{\circ}$

One infection occurred, one required

Five patients in each treatm occasional pain or pain on $\mathrm{u}$ hand. Eighteen patients hac much improved function, th function and three hand der post-operatively.

Crossed intrinsic transfer re greater ROM

$\mathrm{ADL}=$ Activities of Daily Living, $\mathrm{MCP}=$ metacarpophalangeal, $\mathrm{IP}=$ interphalangeal joints; $\mathrm{RD}=$ radial controlled trial; $\mathrm{ROM}=$ range of motion, $\mathrm{RA}=$ rheumatoid arthritis $\mathrm{OA}=$ osteoarthritis

Table 1. Studies reporting post-operative therapy for metacarpophalangeal arthroplasty, their desi outcomes. 


\section{Discussion}

Sixteen studies described the outcome of different implants and postoperative therapy regimes for MCP arthroplasty. Two of these studies compared the efficacy of one regimen over another, one of these being prospective. Sambandam, Gul and Priyanka (2007)(25) state that 'most studies undermined the importance of this aspect (post-operative treatment) of the procedure' with regards to first carpometacarpal joint arthroplasty, but their claim could be expanded to arthroplasty of other joints of the hand. Post-operative protocols for splinting, activity and exercises are not always well-described, so although there were numerous studies about MCP arthroplasty, they are not included in this review.

Hand therapy for other conditions such as flexor tendon repair also offers multiple postoperative regimens. For example, healing tendons of the hand usually receive motion, but it may be passive, active, or a combination of all of these. The rationale for the various exercise regimens is based on biological healing of the tendon and the strength of the surgical repair, thus its ability to withstand stress without rupturing or gap formation $(26,27)$. These patients usually have normal anatomy preoperatively, leaving few patient variables. Postoperative therapy regimens for MCP arthroplasty are also based on principles of healing and scar formation, but are not prescribed according to the patient's preoperative hand impairment, the type of implant used, or soft tissue balancing procedures performed. For example, patients having undergone extensor tendon rebalancing and recentralization may benefit from avoidance of passive flexion or avoidance of the extremes of flexion, much like a postoperative extensor tendon repair regime. The literature suggests that postoperative therapy for $\mathrm{MCP}$ arthroplasty has not been prescribed in this manner; rather, standard protocols have been designed and applied to consecutive patients.

To compare the efficacy of a new protocol, many patients would be required for allocation to various postoperative therapy groups. Their outcomes would have to be analyzed according to what protocol they received with the implant, surgery, and preoperative status as variables. The first difficulty in forming control or comparison groups lies in the infrequency of this procedure; for example Ring et al.(8) took three years to include 25 hands in their study.

The most common source of bias in the studies was selection bias, which occurs when patients are chosen for treatment or control groups as a result of characteristics that are expected to affect their outcome. Randomization is designed to control the confounding effects of differences between subjects at baseline, and the randomized trial is recommended as the best method of determining treatment efficacy. Here lies the second difficulty in forming control or comparison groups. Patients undergo MCP arthroplasty at all stages of their disease, evidenced by the wide range of motion deficits between the studies of Burr and Pratt, in which the case study patient had nearly normal preoperative MCP motion, and Burr et al., in which some patients had only $25^{\circ}$ of MCP flexion, Measures of pain also varied widely in the latter study, ranging from "zero" to "eight out of ten." These baseline measurements demonstrate the difficulty in obtaining a homogeneous, comparable group of patients with rheumatoid arthritis.

The other three sources of bias described by the Cochrane Collaboration(7) were present in the reviewed studies. Performance bias occurs when patients receive a variation in duration, 
quality, or quantity of the treatment being studied, which was suspected in the continuous passive motion (CPM) study by Ring et al. Ring et al. describe the application of CPM in detail, except passive forces are described as "low" and treatment quantity is described as "as tolerated." As a result, the reader remains unsure of what amount of passive force is ineffective, as well as what quantity of treatment per day is ineffective.

Detection bias is determined if the timing of assessment, the outcome assessment used, or knowledge of the assessor of the patient's previous state could miss any relevant aspect of the outcome. This may have occurred in the study by Groth et al.,(10) in which some preoperative data were unavailable and patients were assessed at different postoperative time frames. Detection and comparison of outcomes between studies are only possible when the same outcome measures are used in a standardized manner. The researchers in this review all measured range of motion, but at different time frames (Table 1). Those who measured pain, cosmesis, and function applied different assessments at different time frames. The challenge of outcome measurement in rheumatology has led to the formation of focus groups such as OMERACT (Outcome Measures in Rheumatoid Arthritis Clinical Trials), who have made recommendations for outcome measures to be used in drug trials. OMERACT recommendations are not fully relevant to hand therapy research; however, the process of forming a focus group, and the development of assessment guidelines that allow comparison between homogeneous patients, is possible (28).

Attrition bias is determined if the loss of patients in the study is significant or varies between the treatment and control groups. This is common in long-term studies involving patients with rheumatoid arthritis, and was experienced by Groth et al.,(10) who were unable to obtain long-term follow-up of the patient group who received their extension protocol. Long-term follow-up is an issue with rheumatoid populations. These patients undergo numerous surgical and drug interventions, while their disease progresses and fluctuates, making the long-term effects of the MCP surgery and therapy difficult to define. Once more, large numbers of patients in each treatment group would be required to decrease the effects of attrition bias and to dilute the effects of subsequent interventions.

The difficulties of past studies guide the planning of future studies. Although the issues of low patient numbers, variable preoperative status, additional surgical and drug interventions, and chronic disease cannot be altered, study designs can. Large randomized trials may not be possible; however, samples of patients, paired according to preoperative status, may be allocated to different treatment protocols. Standardized measurement of pain, cosmesis, impairment, disability, and impact on the patient, made at similar postoperative time frames, would further assist in determining treatment efficacy.

\section{Conclusion}

This review suggests that all regimens contribute toward an increase in MCP motion and an increase in hand function, but despite the efforts of patients and clinicians, hand therapists remain unaware of the most effective postoperative protocol for $\mathrm{MCP}$ arthroplasty or the suitability of each regimen for specific implants and soft-tissue 
procedures. Difficulties in researching this topic include low patient numbers, highly variable preoperative status, lack of guidelines for outcome measures and time frames, and the effects of subsequent interventions received by the patient. The nature and size of the population with rheumatoid arthritis and MCP arthroplasty do not readily fit the randomized, controlled trial design. Paired sample designs are suggested, as well as the formation of standard outcome measures, for better comparison of results between patients.

\section{References}

[1] Krishnan J. The Biomechanical and Anatomical Basis for the Design of a New MCP Joint Prosthesis: [doctoral thesis], Australia: Flinders University School of Biomedical Engineering, 1998.

[2] Beevers DJ, Seedhom BB. Metacarpophalangeal joint prostheses. J Hand Surg. 1995;20B:125-36.

[3] Swanson AB. Silicone rubber implants for replacement of arthritic or destroyed joints in the hand. Surg Clin North Am. 1972;48:1113-27.

[4] Beiber EJ, Weiland AJ, Violenec-Dowling S. Silicone-rubber implant arthroplasty of the metacarpophalangeal joints for rheumatoid arthritis. J Bone Joint Surg [Am]. 1986;68:206-9.

[5] Pereira JA, Belcher HJCR. A comparison of metacarpophalangeal joint silastic arthroplasty with or without crossed intrinsic transfer. J Hand Surg. 2001;26B:22934.

[6] Madden JW, De Vore G, Arem AJ. A rational post-operative program for metacarpophalangeal joint implant arthroplasty. J Hand Surg. 1977;2A:35866.

[7] Clarke M, Oxman AD (eds). Cochrane Reviewers' Handbook 4.1.4. Oxford: The Cochrane Library, issue 4, update software, 2001.

[8] Ring D, Simmons BP, Hayes M. Continuous passive motion following metacarpophalangeal joint arthroplasty. J Hand Surg. 1998;23A:505-11.

[9] Thomsen NOB, Boeckstyns MEH and Leth-Espensen P. Value of dynamic splinting after replacement of the Metacarpophalangeal joint in patients with rheumatoid arthritis. Scand J Plast Reconstr Surg Hand Surg 2003; 37: 113-116.

[10] Groth G, Watkins M, Paynter P. Effect of an alternative flexion splinting protocol on mid-joint ROM [letter]. J Hand Ther. 1996;9:68-9.

[11] Burr N, Pratt AL, Smith PJ. An alternative splinting and rehabilitation protocol for metacarpophalangeal joint arthroplasty in patients with rheumatoid arthritis. J Hand Ther. 2002;15:41-7.

[12] Burr N, Pratt AL. MCP joint arthroplasty case study: the Mount Vernon static regime. Br J Hand Ther. 1999;4:137-40.

[13] Escott B, Ronald K and Judd M. NeuFlex and Swanson Metacarpophalangeal Implants for Rheumatoid Arthritis: Prospective Randomized, Controlled Clinical Trial Journal of Hand Surgery Volume 35, Issue 1, 2010, Pages 44-51. 
[14] Harada Y, Okumura S and Takahashi Y. Hand Therapy After Metacarpophalangeal Joint Implant Arthroplasty in Rheumatoid Hand. Journal of Hand Therapy 2010Volume 23, Issue 4, Pages e2-e3.

[15] Chung KC, Kotsis SV, and Kim HM, A Prospective Outcomes Study of Swanson Metacarpophalangeal Joint Arthroplasty for the Rheumatoid Hand. J Hand Surg Am. 2004 July; 29(4): 646-653.

Pettersson K, Wagnsjo P, Hulin E. NeuFlex compared with Sutterprostheses: a blind, prospective, randomized comparison of Silastic metacarpophalangeal joint prostheses. Scand J Plastic Reconstr Surg 2006;40:284 -290.

[16] V.A. Nuñez and N.D. Citron. Short-term results of the Ascension ${ }^{\mathrm{TM}}$ pyrolytic carbon metacarpophalangeal Joint replacement arthroplasty for osteoarthritis. Chirurgie de la Main. Volume 24, Issues 3-4, June-August 2005, Pages 161164.

[17] Rettig LA, Luca L and Murphy MS. Silicone Implant Arthroplasty in Patients With Idiopathic Osteoarthritis of the Metacarpophalangeal Joint J Hand Surg 2005;30A:667-672.

[18] Moller K, Sollerman C, Geijer M, Kopylov P, Ta“gil M.Avanta versus Swanson silicone implants in the MCP joint -a prospective, randomized comparison of 30 patients followed for 2 years. J Hand Surg 2005;/30B:/8-13.

[19] Parkkila T, Belt EA, Markku Hakala M, Kautiainen H and Leppilahti J. Comparison of Swanson and Sutter Metacarpophalangeal Arthroplasties in Patients With Rheumatoid Arthritis: A Prospective and Randomized Trial Journal of Hand Surgery Volume 30, Issue 6, 2005, Pages 1276-1281

[20] Thomsen NOB, Michel E. H. Boeckstyns MEH and Leth-Espensen P. Value of dynamic splinting after replacement of the metacarpophalangeal joint in patients with rheumatoid arthritis. Scand J Plast Reconstr Surg Hand Surg 2003; 37: 113-116

[21] Radmer S, Andresen S and Sparmann M. Poor experience with a hinged endoprosthesis (WEKO) for the metacarpophalangeal joints. Acta Orthop Scand 2003; 74 (5): 586590.

[22] Ishikawa H, Murasawa A, Hanyu T (2002). The effects of activity andtype of rheumatoid arthritis on the flexible implant arthroplasty ofthe metacarpophalangeal joint. Journal of Hand Surgery, 27B (2):180-183.

[23] Stothard J, Thompson AE and Sherris D. Correction of ulnar drift during silastic metacarpophalangeal joint arthroplasty. J Hand Surg (British Volume) 16B: 6165.

[24] Sambandam SN Analysis of methodological deficiencies of studies reporting surgical outcome following cemented total-joint arthroplasty of trapezio-metacarpal joint of the thumb. Int Orthop 2007 31:639-45.

[25] Zhao C, Amadio PC, Zobitz ME, Momose T, Couvreur P, An K-N. Effect of synergistic motion on flexor digitorum profundus tendon excursion. Clin Orthop. 2002;396:223-30.

[26] Tang JB, Wang B, Chen F, Chen Zhong Pan, Xie RG. Biomechanical evaluation of flexor tendon repair techniques. Clin Orthop. 2001;386:252-9. 
[27] Tugwell P, Boers M. OMERACT conference on outcome measures in rheumatoid arthritis clinical trials: conclusion. J Rheumatol. 1993;20:590-1. 


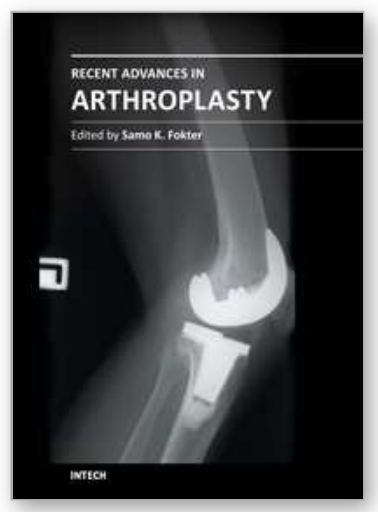

\author{
Recent Advances in Arthroplasty \\ Edited by Dr. Samo Fokter
}

ISBN 978-953-307-990-5

Hard cover, 614 pages

Publisher InTech

Published online 27, January, 2012

Published in print edition January, 2012

The purpose of this book was to offer an overview of recent insights into the current state of arthroplasty. The tremendous long term success of Sir Charnley's total hip arthroplasty has encouraged many researchers to treat pain, improve function and create solutions for higher quality of life. Indeed and as described in a special chapter of this book, arthroplasty is an emerging field in the joints of upper extremity and spine. However, there are inborn complications in any foreign design brought to the human body. First, in the chapter on infections we endeavor to provide a comprehensive, up-to-date analysis and description of the management of this difficult problem. Second, the immune system is faced with a strange material coming in huge amounts of micro-particles from the tribology code. Therefore, great attention to the problem of aseptic loosening has been addressed in special chapters on loosening and on materials currently available for arthroplasty.

\title{
How to reference
}

In order to correctly reference this scholarly work, feel free to copy and paste the following:

Nicola Massy-Westropp (2012). Postoperative Therapy for Metacarpophalangeal Arthroplasty, Recent Advances in Arthroplasty, Dr. Samo Fokter (Ed.), ISBN: 978-953-307-990-5, InTech, Available from: http://www.intechopen.com/books/recent-advances-in-arthroplasty/postoperative-therapy-formetacarpophalangeal-arthroplasty

\section{INTECH}

open science | open minds

\author{
InTech Europe \\ University Campus STeP Ri \\ Slavka Krautzeka 83/A \\ 51000 Rijeka, Croatia \\ Phone: +385 (51) 770447 \\ Fax: +385 (51) 686166 \\ www.intechopen.com
}

\author{
InTech China \\ Unit 405, Office Block, Hotel Equatorial Shanghai \\ No.65, Yan An Road (West), Shanghai, 200040, China \\ 中国上海市延安西路65号上海国际贵都大饭店办公楼 405 单元 \\ Phone: +86-21-62489820 \\ Fax: +86-21-62489821
}


(C) 2012 The Author(s). Licensee IntechOpen. This is an open access article distributed under the terms of the Creative Commons Attribution 3.0 License, which permits unrestricted use, distribution, and reproduction in any medium, provided the original work is properly cited. 